\title{
Tradução
}

\section{Gesto musical e a construção interpretativa de obras contemporâneas brasileiras*}

Resumo

Este estudo tem como objetivo delinear questões que ainda vêm desafiando a pesquisa acadêmica em performance musical, sobretudo as relacionadas ao gesto do performer e às condições gestuais que determinam a performance do repertório acadêmico contemporâneo para piano. Ao se falar em execução instrumental, a maneira de fazê-la, ou seja, o modo de interpretar, de tocar e de planejar a performance mostra-se relevante. O desenvolvimento consciente da sequência de gestos que constituirá a performance instrumental determina, de modo significativo, a construção interpretativa. Isto ocorre porque a imaginação sonora conduz o intérprete à escolha dos movimentos que produzirão os diferenciados sons intencionados, assim como os movimentos gestuais implicarão configurações sonoras imaginadas. Esta questão aflora ao se abordar a interpretação da música contemporânea, a qual contém um repertório vasto, crescente e apresenta tendências diversas. Por se tratar de uma prática interpretativa em construção, não cristalizada em modelos estéticos consagrados, ela demanda do performer decisões interpretativas não previstas no modelo pedagógico que o formou. Assim sendo, os desafios postos pelo repertório contemporâneo, que avivam o processo de aquisição de competências interpretativas, enfatizados nesta pesquisa, contribuem sobremaneira para a pedagogia da performance musical, implicando aportes para o reconhecimento do gesto musical dentro de uma rede de elementos de interações não convencionais que estruturem a produção do próprio gesto musical. A familiaridade, a vivência e o conhecimento adquiridos pelo performer acerca do potencial expressivo e das tendências estilísticas, contidas no texto da obra, determinam seu entendimento musical e, consequentemente, a qualidade da execução instrumental. O referencial teórico respalda-se nas considerações e nos preceitos de George Kochevitsky (1967), Leonard Meyer (1989), Robert Hatten (2004), Marc Leman (2008), entre outros.

\section{Palavras chave: interpretação musical, construção interpretativa, gesto musical, música brasileira contemporânea}

\footnotetext{
* Traducción del original “The Musical Gesture and the Interpretative Construction of Contemporary Brazilian Musical Works”. Previamente publicado en Parcutt, R y Sattamann, S. (Eds.) (2018). Proceedings of ICMPC15/ESCOM10. Graz, Austria: Centre for Systematic Musicology. University of Graz, 256-260. Traducción realizada por el autor. Todos los permisos de traducción y reproducción fueron otorgados para la presente publicación.
}

Epistemus - Revista de estudios en Música, Cognición y Cultura. ISSN 1853-0494

http://revistas.unlp.edu.ar/Epistemus

Epistemus es una publicación de SACCoM (www.saccom.org.ar).

Vol. 7. No 1 (2019) | 115-126

Recibido: 08/11/2018. Aceptado: 03/05/2019.

DOI (Digital Object Identifier): https://doi.org/10.24215/18530494e006:

Esta obra está bajo una Licencia Creative Commons Atribución - No Comercial - Sin Obra Derivada 4.0 Internacional de Creative Commons. Puede copiarla, distribuirla y comunicarla públicamente siempre que cite su autor y la revista que lo publica (Epistemus - Revista de estudios en Música, Cognición y Cultura), agregando la dirección URL y/o un enlace a este sitio: http://revistas.unlp.edu.ar/Epistemus. No la utilice para fines comerciales y no haga con ella obra derivada.

La licencia completa la puede consultar en https://creativecommons.org/licenses/by-nc-nd/4.0/ 


\section{TATIANA DUMAS MACEDO}

Universidade Federal do Rio de Janeiro

tatianadumas@gmail.com

\section{Traducción}

\section{Gesto musical y la construcción interpretativa de obras contemporáneas brasileñas}

\section{Resumen}

Este estudio tiene como objetivo delinear cuestiones que aún vienen desafiando la investigación académica en performance musical, sobre todo lo relacionado com el gesto del ejecutante y las condiciones gestuales que determinan la performance del repertorio académico contemporáneo para piano. Al hablar en ejecución instrumental, la manera de hacerlo, es decir, el modo de interpretar, de tocar y de planificar la performance, se muestra relevante. El desarrollo consciente de la secuencia de gestos que constituirá el desempeño instrumental determina, de modo significativo, la construcción interpretativa. Esto ocurre porque la imaginación sonora conduce al intérprete a la elección de los movimientos que producirán los diferentes sonidos intencionados, así como los movimientos gestuales implicarán configuraciones sonoras imaginadas. Esta cuestión aflora al abordar la interpretación de la música contemporánea, la cual contiene un repertorio vasto, creciente y presenta tendencias diversas. Por tratarse de una práctica interpretativa en construcción, no cristalizada en modelos estéticos consagrados, demanda del ejecutante decisiones interpretativas no previstas en el modelo pedagógico que lo formó. Por lo tanto, los desafíos planteados por el repertorio contemporáneo, que avivan el proceso de adquisición de competencias interpretativas, enfatizadas en esta investigación, contribuyen sobremanera a la pedagogía de la performance musical, implicando aportes para el reconocimiento del gesto musical dentro de una red de elementos de interacciones no convencionales que estructuren la producción del propio gesto musical. La familiaridad, la vivencia y el conocimiento adquiridos por el ejecutante acerca del potencial expresivo y de las tendencias estilísticas contenidas en el texto de la obra, determinan su entendimiento musical y, consecuentemente, la calidad de la ejecución instrumental. El referencial teórico se respalda en las consideraciones y en los preceptos de George Kochevitsky (1967), Leonard Meyer (1989), Robert Hatten (2004), Marc Leman (2008), entre otros.

\section{Palabras Claves:}

interpretación musical, contrucción interpretativa, gesto musical, música brasilera contemporánea 


\section{Introdução}

Interpretar não é um ato isolado que ocorre apenas no confronto com uma obra de arte. Antônio Ferraz (2013) esclarece que interpretar é algo que é feito ao se relacionar com o mundo, sendo, por conseguinte, um ato contínuo de diálogo e experiência. As construções das interpretações são, portanto, emergentes na interação e não predeterminadas estruturalmente. Tendo isso em vista, a interpretação musical, conforme Anne Roubet (2011), é entendida como a atualização sonora de uma peça musical.

Leonard Meyer (1989) explana que o intérprete é um ser histórico e interpreta em função de sua cultura, de tradições herdadas, da educação recebida, do grau de familiaridade e sensibilidade ao estilo musical ou à cultura em questão. Ao se deparar com o texto escrito da música -a partitura- o intérprete está diante de uma obra de representação das ações que gerarão a obra musical, no caso de partituras prescritivas, e/ou dos efeitos da obra musical, no caso de partituras descritivas. A partir daí, conforme José Augusto Mannis (2012), o intérprete procederá à identificação dos elementos musicais que serão percebidos durante a leitura. Para a realização sonora, ele se utilizará de um repertório de gestos previamente apreendido, aprendido e automatizado. A maneira como o intérprete estrutura sua performance, quais elementos busca salientar, o que percebeu, a estratégia para a realização sonora refletem o modo como ele ouve a música e determina sua concepção da obra musical. O nível do entendimento musical do performer e, consequentemente, da qualidade da execução, dependerá da vivência, da intimidade, do conhecimento adquiridos pelo músico sobre as intenções expressivas e as tendências estilísticas da obra (Meyer, 1989; Silverman, 2008; Mannis, 2012). Assim, o modo como o corpo encarna a concepção da obra e seu estado emocional constituirão a singularidade de sua interpretação.

A música acadêmica contemporânea e, no caso desta pesquisa, a música brasileira para piano contêm um repertório vasto, crescente, que engloba tendências diversas. Por apresentar-se, aparentemente, menos homogênea do que em períodos passados, com relação a um conjunto de convenções, sentidos, valores preestabelecidos por uma prática interpretativa consagrada, demanda do performer atitudes interpretativas diferentes daquelas a que está habituado, para as quais a formação tradicional não o preparou. A questão textural, por exemplo, entendida, desde a Idade Média, como um procedimento usual na composição, torna-se significativa na técnica composicional, devido ao colapso do sistema tonal, em que as construções das melodias e das progressões harmônicas passaram a ser elaboradas descontinuadamente em forma de colagens. À vista disso, Souza (2004) explica que a percepção de boa parcela da música dos séculos XX e XXI passa a acontecer por meio dos blocos sonoros e pela maneira como se relacionam ou se transformam no decorrer da composição, embaraçando o reconhecimento do 
gesto musical a ser utilizado dentro de uma rede de elementos de interações não convencionais, que conferem estrutura à produção do próprio gesto musical.

O objetivo do presente estudo é expor as dificuldades que o texto -a partituraimpõe ao intérprete no reconhecimento do gesto musical dentro de uma rede de elementos de interações não convencionais, que estruturam a produção do próprio gesto musical. Em consequência das várias significações encontradas, faz-se pertinente a conceituação de gesto musical.

\section{O conceito de gesto musical}

Consoante o conceito amplo de "gesto" preconizado por autores como Marc Leman e Rolf Godøy (2010), José Mannis (2012), Vilém Flusser (2014), ele consiste no movimento do corpo, representando uma série de atividades organizadas para alcançar determinado fim, ou seja, expressar intenções, sentimentos, ideias. $\mathrm{O}$ indivíduo incorpora, pois, os movimentos que se realizam em função de sua interação com o meio ambiente. Indo ao encontro de um referencial clássico, porém ainda atual e relevante no campo das práticas interpretativas, como o de Gerd Kaemper (1968), o qual esclarece que a interação de um indivíduo com o meio ambiente ocorre por meio dos movimentos que carrega armazenados consigo desde seus primeiros momentos de vida. Ao se desenvolver, ele apreende os movimentos que lhe convêm e descarta os que não lhe servem mais.

Partindo de um raciocínio que visa aumentar e refinar, cada vez mais, as potencialidades do performer, Kochevitsky (1967) elucida que o estímulo visual de um trecho musical impele a elaboração mental de uma imagem sonora prévia, a qual induzirá a escolha do gesto adequado à produção do som solicitado. Ou seja, a imaginação sonora, provocada pelo estímulo visual, conduzirá o intérprete à escolha do movimento que produzirá os diferenciados sons pensados por meio da escolha dos diferentes toques pertinentes ao campo da técnica pianística. O gesto escolhido e realizado efetivará a propagação do som real no espaço, que será devidamente avaliado pelo ouvido, verificando, dessa maneira, sua coerência com a ideia musical escrita. O autor acrescenta que a escrita musical, por se tratar de uma cadeia de estímulos, incita as células da região visual do córtex que imediatamente repassam tais estímulos à região auditiva. Com o treino, as células da região auditiva associam-se fisiologicamente às células da área motora, produzindo reação ou resposta motora.

Kochevitsky (1967) explica que os estímulos chegam até o indivíduo como sistemas de sinais (terminologia antiquada baseada na teoria da informação dos anos 1950). O primeiro sistema de sinais é formado pelos estímulos externos que chegam diretamente aos órgãos receptores como impressões e sensações do mundo natural circundante. $\mathrm{O}$ segundo é formado pelo simbolismo verbal. Por meio 
dele, o ser humano é capaz de executar novos movimentos, recriar atos motores baseados tanto em demonstrações e descrições como em estímulos de sinais. A imaginação interior do som passa, portanto, a ser o sinal que representa uma ação ou conjunto de ações, o qual provoca a reação motora. Por isso, ao se realizar uma ideia musical, o ponto de partida é a imagem sonora, a qual, por ser um estímulo auditivo, sempre deverá vir à frente da reação motora, tanto no estudo quanto na performance pianística. O som resultante deste movimento é rapidamente avaliado pelo ouvido e, com o auxílio da sensação tátil, achará a justa dosagem para controlar a reação motora de acordo com a intenção da imaginação sonora prévia (Kochevitsky, 1967).

Em um contexto em que o conjunto de convenções preestabelecidas para a prática interpretativa apresenta-se lacônico, como na música contemporânea brasileira, a questão está na constituição dessa imagem sonora, no reconhecimento e na determinação do gesto musical, dentro de uma rede de interações constituídas entre os elementos formantes. Conforme explicita Robert Hatten (2004), o gesto musical, tanto a partir da escrita quanto a partir da performance instrumental, é uma forma de manipulação de múltiplos parâmetros sonoros e inscreve-se na matéria sonora de maneiras inequívocas na partitura, evadindo a notação musical. Assim, o mesmo gesto musical pode ser realizado por diferentes movimentos corporais. Reconhecer um gesto é reconhecer a configuração desta rede. Tal busca por relações confere estrutura ao gesto musical, fazendo parte do próprio processo cognitivo que procura compreender a composição musical (Hatten, 2004; Steuernagel, 2015).

\section{A construção interpretativa}

A fim de expor algumas dificuldades do performer nas construções interpretativas das obras de estética contemporânea -normalmente não contempladas nos ciclos de formação acadêmico-profissional de performers- apresentam-se três excertos de obras, para instrumentações diferentes com piano, de compositores brasileiros distintos que demandam abordagens interpretativas diversas.

A obra Os abacaxis não voam foi composta, em 2001, por Guilherme Nascimento para piano solo. A peça foi escrita toda com clave de sol, na região médio-aguda do piano, em que a nota mais grave é C\#3. Os compassos são determinados por tempo cronometrado com indicação variada de segundos. De modo geral, deve ser executada com toque legato e soar bastante suave, com dinâmicas que vão de pianissimo (2p) a uma intensidade extremamente suave (15p). No meio da peça, um trecho com maior densidade de elementos é realizado com um forte subito, conectando-se a outro de menor densidade em $4 p$ subito, iniciando a parte mais delicada da obra em termos de dinâmica. Ao final, há uma configuração que pa- 
rece sintetizar os elementos da obra, proferindo um pouco mais de movimento e de intensidade, antes de finalizar de forma etérea.

A melodia apresentada nos compassos 15-19 (Figura 1), conforme nota do compositor na partitura, deve ser executada com toque legatissimo e soar lenta, calma, muito expressiva, com dinâmica bastante suave (4p). Após a nota Ab3, que apresenta um sinal de tenuto, no final do compasso 15, há uma linha horizontal cruzando os limites deste compasso até o início do compasso seguinte, indicando que a nota em questão deve ser prolongada por toda a extensão da linha. $\mathrm{O}$ mesmo ocorre com a última nota da melodia (Bb5), que deve ser prolongada até o fim do compasso 19. A questão explicitamente aqui apresentada pelo compositor está em como o intérprete, tendo em vista o tempo cronometrado referente a cada compasso, irá definir a duração de cada nota, evitando padrões rítmicos, a fim de constituir a melodia. Contudo, a realização de uma melodia não é só uma questão de escolha de durações de alturas predeterminadas. Essa é apenas uma questão, dentre tantas outras sem respostas, que emergem diante da partitura, a ver: como será realizada essa dinâmica, marcada na partitura, se o instrumento piano, de modo geral, não é capaz de executar dinâmicas suaves além de $p p p$ ? Como há o decaimento do som logo após sua realização, como este será prolongado por tantos segundos, em dinâmica bastante suave, mesmo com a utilização do pedal de sustain? Qual será a imaginação sonora do compositor? Em que momento dos compassos as notas serão executadas? Como será realizada a melodia do excerto da Figura 1? Que relações devem ser feitas? Há alguma polarização, hierarquização? Qual será o direcionamento da melodia? Essa dinâmica suave deve ser mantida constantemente ou possuírá microdinâmicas? Dentro do toque legato, em uma dinâmica bastante suave, quais tipos de articulação, de apoio, de gesto, que não estão escritos, podem ser realizados?

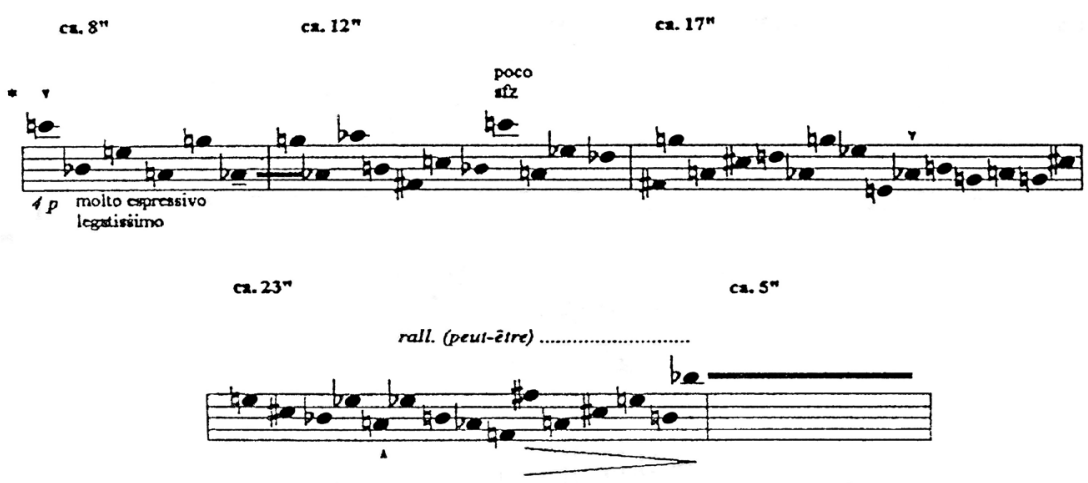

Figura 1. Compassos 15-19 da obra Os abacaxis não voam de Guilherme Nascimento (2001) para piano solo. 
A obra Melodia foi escrita, em 2010, por Edson Zampronha (Figura 2) para cinco instrumentos, incluindo um piano. Todos os instrumentos devem ser capazes de tocar de G\#2 a F5. Na partitura, encontram-se seis retângulos. Em cada um deles existe uma nota de entrada à esquerda e uma nota de saída à direita. Essas notas de entrada e de saída são conectadas por outras notas estruturais, que estão ligadas por linhas, formando uma longa melodia. A leitura da peça ocorre, então, começando da nota de entrada e movendo-se à nota de saída, seguindo-se as linhas que conectam uma nota à outra. A sequência de notas a ser realizada fica a critério do intérprete. Movimentos em direção e sentido inversos são permitidos. O compositor esclarece, no texto explicativo em que indica como se deve ler e tocar a partitura - a bula -, que as notas estruturais devem ser ricamente ornamentadas e esses ornamentos podem ser "acordes, clusters, movimentos melódicos rápidos e breves, diferentes tipos de ataques, mudanças de dinâmica, mudanças de timbre, e assim por diante" (Zampronha, 2010, p.2-3). Eles podem ser executados em qualquer oitava e não estão restritos às notas do retângulo, mas é enfatizado que devem se dirigir às notas estruturais, realçando-as. Após o início da música, cada instrumentista se encaminhará à nota de saída de forma independente. Contudo, todos os músicos passarão de um retângulo para outro de forma sincronizada. Quando um performer chega à nota de saída, ele deve tocá-la repetidamente ou com tremolo, quase sem ornamentos ou com ornamentos muito simples, indicando aos outros músicos que devem se encaminhar à nota de saída, no entanto sem realizarem o movimento de salto para alcançá-la e sim por meio dos movimentos permitidos, ou seja, dos caminhos indicados pelas linhas. Quando todos os músicos chegam à nota de saída, é realizada a mudança de retângulo. A indicação de dinâmica, dentro de cada retângulo, não está determinada. No entanto, dois tipos de dinâmicas globais são sugeridos, os quais, de modo geral, propõem um grande crescendo de $\not p$ a $f f$, com retorno a $p p$ no último retângulo. Por fim, há o esclarecimento que o tempo de duração da obra deve ser de, aproximadamente, seis minutos.

Esta peça apresenta uma extensa bula, entretanto, apesar de toda instrução dada, muitos questionamentos com relação ao planejamento da construção interpretativa permanecem sob dois pontos de vista: o pessoal e o coletivo. Ou seja, como será realizada a parte do piano e como esta parte será conectada às partes dos outros instrumentos, de forma a constituir uma única música?

Esta composição apresenta-se bastante livre em termos de execução, porém, dentro desta liberdade, há uma estrutura basal que gera uma organização, uma lógica para elaboração musical. Como essa estrutura será realizada? Qual será a duração de cada retângulo? Qual dinâmica será adotada em cada um? Há algum instrumento que deverá sobressair em determinado momento ou a peça será realizada como uma massa sonora, um bloco sonoro, em que todos realizam suas ideias dentro da mesma intensidade? Como essa longa melodia, de dentro do 
retângulo, deverá soar? Para que soe da forma escolhida, como deverá ser organizada? A forma escolhida é a melhor em termos de ideário sonoro e de execução em conjunto? Como as notas estruturais serão ornamentadas? Quais ornamentos serão utilizados e como eles serão empregados? É possível a realização de uma sonoridade tonal ou deve ser evidenciada uma sonoridade atonal? Como fazer para que cada retângulo não soe igual, repetitivo? Será que o compositor quer um padrão?

Ressalte-se que, após a elaboração e a predeterminação de possíveis respostas a estas indagações, a interação com os outros músicos irá, provavelmente, modificá-las, em um processo contínuo e permanente de retroalimentação. O performer deve estar atento e aberto a estabelecer novas relações resultantes desta interatividade.

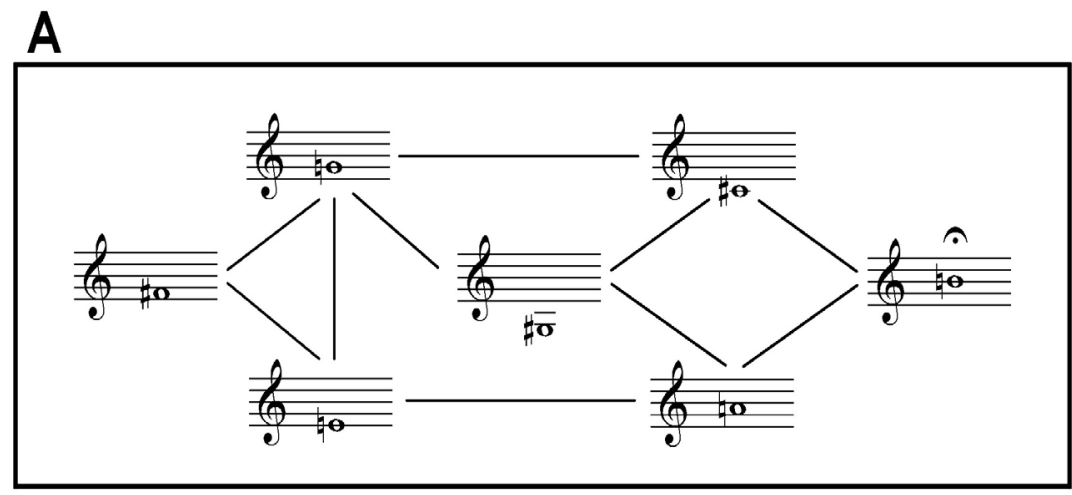

Figura 2. Trecho/ retângulo inicial da obra Melodia de Edson Zampronha (2010), para dois a cinco instrumentos incluindo piano.

A obra Noite do Catete 14 foi composta, em 2016, por LC Csekö, para voz, clarinete baixo, violão, guitarra elétrica, piano ampliado, percussão e light installation. Ela está escrita com notação gráfica híbrida e mensurada em cronometragens regulares de circa 5 segundos. Por esse motivo, cada símbolo utilizado na peça é apresentado no início da partitura, na bula, juntamente com a especificação do material a ser utilizado e a maneira de execução. É utilizado o piano ampliado, mas sem preparação. Para a realização de alguns elementos/efeitos sonoros são necessárias a aquisição e a manipulação de determinados objetos - lâminas de plástico e metal, baquetas, copos de vidro, etc. - não usuais na prática pianística, para produzirem sons dentro do piano, na harpa. O compositor também inseriu, 
na capa da partitura, epígrafes com excertos de poesias para nortear a interpretação da peça.

Os elementos sonoros da obra são escritos sobre trigramas, cujas linhas, de baixo para cima, indicam as regiões grave, média ou aguda, em que devem ser executados. No caso do piano, há dois trigramas que fazem alusão às regiões das claves de sol e de fá. Não existem compassos. Há marcações, de modo geral, regulares que indicam tempos cronometrados de circa cinco segundos. Os sons demandados pelo compositor são escritos dentro de retângulos de improvisação de simile e devem ser realizados até a interrupção do prolongamento da linha espessa ligada ao retângulo. O contraponto de dinâmica é rico em detalhes, os quais devem ser realizados com precisão para que haja a efetivação dos blocos sonoros do amálgama sonoro elaborado pelo compositor.

O retângulo apresentado na Figura 3 expõe o último conjunto de elementos sonoros da parte de piano. Ele deve ser executado por circa vinte e cinco segundos. Neste retângulo, são realizados seis gestos: 1) friccionar longitudinalmente as cordas graves do piano, com utilização de lâmina de plástico duro ou metal; 2) executar um cluster no teclado do piano; 3) percutir, com ritmo irregular, as cordas do piano, com baquetas de xilofone de cabeça dura; 4) friccionar as cordas do piano, em sentido longitudinal, com copo de vidro ou blues bottleneck); 5) executar, novamente, um cluster no teclado do piano; 6) ferir as cordas do piano, utilizando lâmina de plástico duro ou metal, no sentido horizontal/ paralelo ao teclado. Todos os gestos aqui citados são realizados com o acionamento do pedal de sustain determinado previamente.

O primeiro dilema que aparece, quando o intérprete se coloca diante de uma obra gráfica, é o conhecimento e o reconhecimento dos grafismos e da automação dos gestos musicais que eles representam, ao longo da partitura. Como esses efeitos devem soar? Estão sendo utilizados objetos correspondentes aos solicitados? Os gestos musicais estão de acordo com os pretendidos pelo compositor e estão produzindo a sonoridade idealizada por ele? Os efeitos sonoros estão sendo realizados nas durações, nos andamentos corretos e nas regiões indicadas? Estão ritmicamente irregulares e/ou regulares o suficiente? No caso do piano, grande parte dos efeitos sonoros é realizada dentro da harpa do instrumento, requerendo que o performer toque em pé e acione o pedal, em uma posição não usual e um tanto quanto desconfortável para o pianista. Ou, ainda, que ele alterne execuções no teclado e na harpa do piano, dificultando a coordenação dos gestos e a manutenção interna do tempo. Como se dará, então, a coordenação dos gestos musicais e a manipulação dos objetos? Como manter a sensação temporal? 


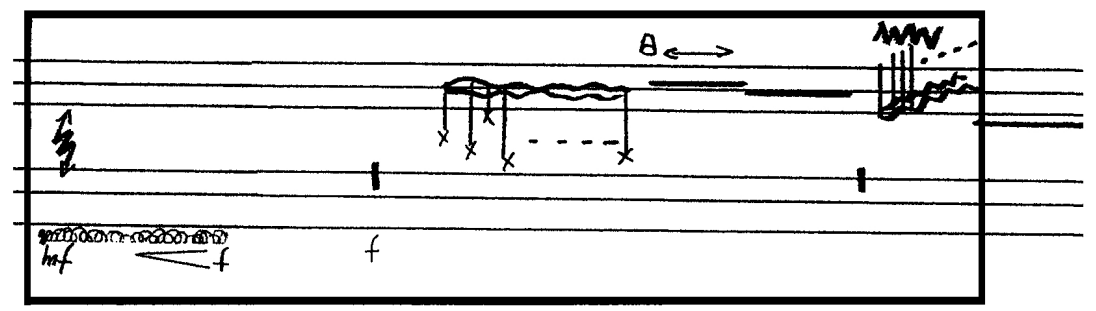

Figura 3. Último retângulo de materiais da parte de piano da obra Noite do Catete 14 de LC Csekö (2016), para voz, clarinete baixo, violão, guitarra elétrica, piano e percussão.

Pelos excertos apresentados, percebe-se que a construção do significado musical considera o corpo na participação da constituição deste sentido. A experiência de um gesto musical passa, então, pela compreensão da notação, da correlação dos gestos por meio do domínio sensório-motor, da dimensão expressiva e da vivência do performer, evocando o universo cultural do instrumentista, assim como sua identidade subjetiva e particular, seus afetos, a intensidade de sua experiência, seus valores, costumes e comportamentos.

\section{Conclusão}

Por meio do exposto, depreende-se que a experiência e a imaginação são partes formantes da criatividade. No primeiro momento, no contexto da estética contemporânea, o performer não possui um plano cognitivo, um repertório de resolução de problemas específico para as questões inusitadas que se apresentam, tais como inserção de elementos composicionais na obra, seleção e criação de materiais, criação de relações entre elementos, participação da definição estrutural da obra. Estabelecer a estrutura formal da peça, produzir os sentidos que constituirão seu entendimento, reconhecer a rede de interações entre sentidos e gestos, criar estratégias para realizar e articular os gestos constituintes da performance (que evidenciarão os sentidos intencionados) são qualidades a serem desenvolvidas pelo performer no processo de aprendizado da interpretação. Assim sendo, se reconhece que, diante dos desafios impostos pelo repertório contemporâneo, torna-se mais claro o processo de aquisição de competências interpretativas, apresentando-se como uma contribuição valiosa da prática da música contemporânea para a pedagogia da performance musical.

Intérpretes aprendem a aprender, desenvolvendo estratégias para sua prática cotidiana e sua performance. O processo criativo visa à resolução de problemas que se apresentam a cada nova obra. Isto se define cognitivamente como a formação de novos caminhos e de novas soluções para as dificuldades que surgem, em prol de um resultado, de um produto final. Em virtude disso, defende-se aqui a ideia 
de que quanto maior a experiência com as demandas da construção interpretativa da música atual, mais subsídios e recursos o intérprete terá para a atividade criativa que, de modo geral, essencializa sua produção.

\section{Referências}

Csekö, L.C. (2016). Noite do Catete 14. Edição do autor. 1 partitura (18 p.).

Ferraz, A. M. (2013). A liberdade na interpretação. Revista Interfaces, 1(18), 36-52.

Flusser, V. (2014). Gestures. (N. A. Roth, Trans.) Minneapolis, MN, USA: University of Minnesota Press.

Hatten, R. (2004). Interpreting Musical Gestures, Topics and Tropes. Blooming e Indianopolis: Indiana University Press.

Kaemper, G. (1968). Techniques pianistiques. Francia: Alfhonse Leduc et Cie - Éditions Musicales.

Kochevitsky, G. (1967). The art of piano playing: a scientific approach. Van Nuys: SummyBirchard Inc.

Leman, M. (2008). Embodied Music Cognition and Mediation Tecbnology. Cambridge, Massachusetts: The MIT Press.

Leman, M., \& Godøy, R. I. (2010). Why study musical gesture? En M. Leman y R. I. Godøy (Eds.), Musical gestures: Sound, movement, and meaning (pp. 3-11). Nueva York: Routledge.

Mannis, J. A. (2012). Processo criativo: do material à concretização, compreendendo interpretação-performance. Teoria crítica e música na atualidade (Série Simpósio Internacional de Músicologia da UFRJ), 2, 231-242.

Meyer, L. (1989). Style and Music: theory, history and ideology. Chicago: The University of Chicago Press.

Nascimento, G. (2001). Abacaxis não voam. Edição do autor. 1 partitura (6 p.).

Roubet, A. (2011). Interprétation. En: C. Accaoui (Ed.), Éléments d'esthétique musicale: notions, formes et styles en musique (pp. 257-272). Paris: Actes Sud / Cité de la musique.

Silverman, M. (2008). A performer's creative processes: implications for teaching and learning musical interpretation. Music Education Research, 10(2), 249-269.

Souza, A. R. (2004). Ação e significação: Em busca de uma definição de gesto musical. São Paulo: Instituto de Artes, Universidade Estadual Paulista (UNESP). 
Steuernagel, M. S. (2015). O gesto na composição musical. Revista Vórtex, 3(1), 146158.

Zampronha, E. (2010). Melodia. Edição do autor. 1 partitura (5 p.).

\section{Acerca de la autora}

\section{Tatiana Dumas Macedo}

\section{tatianadumas@gmail.com}

Tatiana Dumas - Doutoranda em Música (Processos Criativos), Mestre e Bacharel em Música pela UFRJ e Licenciada em Educação Artística - Música pela UNIRIO. Exerce intensa atividade pianística, interpretando repertório contemporâneo, especialmente brasileiro, paralelamente à prática docente. Sua prática camerística lhe proporcionou a realização de primeiras audições de obras de compositores renomados e jovens compositores, dentre eles: Almeida Prado, Armando Lobo, Fábio Bizzoni, LC Csekö, Marcos Nogueira, Marisa Rezende, Tato Taborda, Thiago Sias, Yahn Wagner. Ao longo de sua carreira, vem participando de Festivais e Mostras de Música Contemporânea Brasileira tais como, 'Bienal de Música Brasileira Contemporânea' e 'Panorama da Música Brasileira Atual'. Apresentou-se com o 'Cron Ensemble' nos mais importantes centros musicais das regiões Sul, Sudeste, Nordeste e Centro-Oeste do país por meio de Projetos de Circulação de Música de Concerto instituídos pela Funarte. 